\title{
Glaucoma Detection Technique in Retina-A study
}

\author{
Shilpa Kaushal ${ }^{1}$, Sunil Datt Sharma², Shruti Jain ${ }^{3}$ \\ 1, 2, 3 Department of Electronics and Communication Engineering, Jaypee University of Information Technology, \\ Solan, Himachal Pradesh, India \\ shilpakaushal1993@gmail.com ${ }^{1}, \underline{\text { sunildatt.sharma@juit.ac.in }}^{2}$, jain.shruti15@gmail.com $^{3}$
}

\begin{abstract}
Glaucoma is a disease associated with retina of eye. Presently, millions of human being is suffering from this disease. Early detection of these diseases can save the people from blindness. Therefore, various methods have been developed for its detection. In this paper, we have studied the reported methods and summarized their performance in terms of accuracy of detection.
\end{abstract}

Keywords - Glaucoma, Intraocular Pressure(IOP) , fundus images, early detection, Cup-to-Disk Ratio(CDR).

\section{INTRODUCTION}

Glaucoma is disease related to optic nerve that arises due to deviation in fluid density inside the eye in addition harms the optic nerve $[1,2]$.Glaucoma, an optic nerve disease occurs due to variation increase or decrease in fluid pressure within the eye. The pressure of the normal eye is $21 \mathrm{~mm}$ of $\mathrm{Hg}$ and when the pressure value is higher than $21 \mathrm{mmHg}$ or $2.8 \mathrm{kPa}$, the optic nerve gets damaged leading to vision impairments and blindness. Diagnosis and treatment is based on elevation of Intraocular Pressure (IOP). Due to the buildup pressure in the eye, the nerve cells become compressed eventually leading to permanent vision loss. The anterior chamber of eye is bounded by cornea, iris, pupil and lens which is filled by fluid called aqueous humor. Aqueous humor nourishes the lens and cornea with nutrients, oxygen and provides optimal pressure called as IOP to maintain the shape of the eye. IOP is measured for detecting glaucoma and diagnosis is done by dilated eye examination showing an abnormal amount of cupping [3]. The post symptoms of Glaucoma are seeing halos around lights, vision loss, Redness in the eye, nausea or vomiting, eye pain and narrowed vision (tunnel vision) [4].

About 6 to 67 million people have glaucoma globally [5]. Every year more than 2 million people are affected by Glaucoma in USA. Glaucoma mostly occurs at the age of 40. Glaucoma has been referred to as the "silent thief of sight" because the loss of vision occurs slowly and gradually with no symptoms and warning signs. Worldwide, glaucoma is the second-leading cause of blindness after cataracts [6]. In 2010, 44.7 million people in the world suffered with open angle glaucoma. By 2020 , the prevalence is projected to increase to 58.6 million worldwide [7]. Women are more prone to Closed-angle glaucoma. Bilateral vision loss can negatively affect mobility and interfere with driving. People with primary open angle glaucoma do not have increased mortality rates, or increased risk of cardiovascular death.

The different types of glaucoma are [8]: Normal Tension Glaucoma, Ocular Hypertension, Primary Open Angle Glaucoma, Primary Angle Closure Glaucoma, Secondary Glaucoma, Congenital Glaucoma, Acute Glaucoma, Pigmentary Glaucoma, and Exfoliation and Trauma- Related Glaucoma out of which we are concentrating on Open angle Glaucoma and Angle Closure Glaucoma because the value of IOP is highest in these two cases. Open angle glaucoma is very common among the individuals. Normal Tension Glaucoma is very painful comparative to other and is also termed as a type of Open angle Glaucoma. [9]. This type of glaucoma generally occurs which low IOP in the eye that's why it is termed as low pressure glaucoma. $[10,11,12]$ 


\section{LITERATURE REVIEW :}

In this section, various methods proposed by different authors has been discussed. With this review, best method for early detection of Glaucoma can be chosen.

i. Agarwal et al [13], had proposed an adaptive thresholding method in which features like mean, standard deviation to segment the optic disk to optic cup are extracted from the images which make this method independent of the noise and image quality. This method gives the $90 \%$ accuracy.

ii. Pruthi et al [14] had given a method for Glaucoma detection by the cup to disk ratio (CDR) analysis. The methodology suggested by the author consists of 6 stages involving: pre-processing the data by illuminance correction, blood vessel removal. ROI extraction after pre-processing the images, followed by the feature extraction technique where optic disc extraction, optic cup extraction, morphological operations, ellipse fitting are some of the steps. The method discussed gives $98.12 \%$ accuracy.

iii. Virk et al [15] suggested a simple method i.e. CDR determination for the screening of Glaucoma. The author had specified one threshold value for CDR i.e. 0.5. If the CDR is greater than 0.5 then one can be suspected with Glaucoma. It gives 95\% accuracy. The detection rate for CDR determination was $80 \%$ which needs more improvement.

iv. Gopalkrishnan et al [16] proposed a technique to segment the Optic Disc (OD) Segmentation using Circular Hough Transform and Curve Fitting boundary from the retinal images. It had used a circular Hough transform for the detection of Glaucoma in early stage. But the accuracy of the method was $68 \%$. This method can be extended and improved using the OCT images.

v. Ayub et al [17] had proposed a method of Optic Disc and Cup Segmentation using K mean Clustering. Since for this method, firstly, ROI was being extracted which was further followed by the pre-processing technique which improves the image quality. In this techniques ellipse fitting was used for smoothening the boundary of OC and OD. Further using these techniques CDR was calculated and used for the early detection of Glaucoma. The advanced process gives the accuracy of $92 \%$ for Glaucoma detection.

vi. Sakthivel et al [19], suggested a technique for glaucoma detection using the Histogram Features Detection Technique. In these method different algorithms like Local Binary pattern (LBP) and Daugman's algorithm had been used for the feature extraction of the data. Histogram was performed for both magnitudes as well as phase components in the data. For the classification of the data, Euclidean distance between the feature vectors has been analyzed.

vii. Kolar et al [19] suggested a method depends on the fractal description which was followed by the classification process. For fractal dimensions estimation, two methods were given which explainsdifferent image information. Retinal nerve fibers was analyzed which were taken from the fundus color images. As losses in the retinal nerve fiber was the symptom of the glaucomatous eye, so it can be used as one of the feature for the detection of the Glaucoma.

viii. Acharyaet al [20] presented a technique in which Glaucoma can be detected using combination of Higher Order Spectra (HOS) and texture features obtained from the retinal digital fundus images. These features after z-score normalization are fed to random-forest classifier which can be used clinically for detecting glaucoma accurately with the accuracy of $91 \%$.

ix. Acharya et al [21] proposed a method in which Gabor transform was used where various features were extracted from the retinal fundus images. These features are mean, variance, skewness, kurtosis, energy and Shannon entropies. PCA was done to reduce the dimensionality of the features. This method gives the $93.1 \%$ accuracy. Author had also proposed a GRI which was developed using principal components to classify the 2 classes using 1 number only. This will reduce the complexity and reduce the classification time for the Glaucoma images. 
x. Shishir et al [22] developed a method for the detection of Glaucoma which consists of Empirical Wavelet Transform (EWT) using fundus images. EWT components were used to extract the correntropy features which were ranked depending upon $t$-value feature selection algorithm. $98.33 \%$ accuracy was obtained using Least SVM which decrease to $96.67 \%$ if 3 fold and 10 -fold cross validation was used.

xi. Krishnan et al [23] proposed a method in which they used the texture features for the detection of Glaucoma. In this method, classification accuracy of $91.67 \%$ was obtained using the SVM classifier.

xii. Nyul et al [24] suggested a method in which author followed three steps process i.e. preprocessing, feature extraction and classification for the detection of the Glaucoma. In preprocessing, different methods i.e. illumination correction, vessel improvement and normalization were employed. Different features were extracted using generic method and these features were classified using SVM classifier in which classification accuracy comes to be $80 \%$.

xiii. Bock et al [25] presented a method for the detection which used a standard pattern recognition pipeline with two stage classification. In this method, features extracted were termed as appearance based features which include pixel intensity values, spectral based, texture and histogram model values. In this approach of Glaucoma detection 86\% accuracy was obtained using SVM classifier.

xiv. Mookiah et al [26] presented an automatic detection method for Glaucoma using the HOS and DWT features. These features with SVM classifier were able to detect Glaucoma with an accuracy of $95 \%$. This method can be employed for the earlier detection of glaucoma.

xv. Dua et al [27] presented a method in which texture features like energy signatures were used as the exact and efficient approach for the detection of Glaucoma. In this method, author extracted energy signatures present within the images using 2D DWT feature extraction technique and different feature ranking and feature selection algorithms were followed. 93\% accuracy was obtained using different classifiers like SVM and naïve Bayes classifier with tenfold validation.

xvi. Beaula et al [28] proposed a methodology for the early detection of the Glaucoma using empirical wavelet transform. In this method, author extracted the correntropy features from the EWT components obtained in the feature extraction process. These features were selected using $t$-test algorithm. 95\% Classification accuracy was obtained with the SVM classifier.

xvii. Patil et al [29] proposed a methodology in which the diagnosis was done using the CDR method. In this method, the super pixel classification on the basis of the cup to disc ratio was done to identify Glaucoma. Color contrast improvement and image filtration were the preprocessing techniques used with the segmentation process for the glaucoma detection.

xviii. Dey et al [30] suggested automated glaucoma selection using support vector classification. In this method, images pre-processing techniques like noise removal and contrast enhancement were used. Principal Component Analysis (PCA) method was employed for feature extraction and SVM method for image classification. This method after cross validation gave accuracy rate $96 \%$,

xix. Singh et al [31] suggested a method for glaucoma detection. This method employs various steps for the diagnosis which are pre-processing, feature extraction and classification. 97\% accuracy was obtained when used with SVM classifier.

\section{METHODOLOGY:}

The general flow diagram for the detection process of glaucoma is shown in Figure 1.In this section; different steps involved in the detection of Glaucoma are discussed.

Step 1: First step is to collect the database which can be local (taken from the hospital) and online available database like Stare (maximum 400 images are present), Drones-DB (110 images are 
present). These images are known as retinal fundal images. Table 1 show the different Database used for detection of Glaucoma till yet.

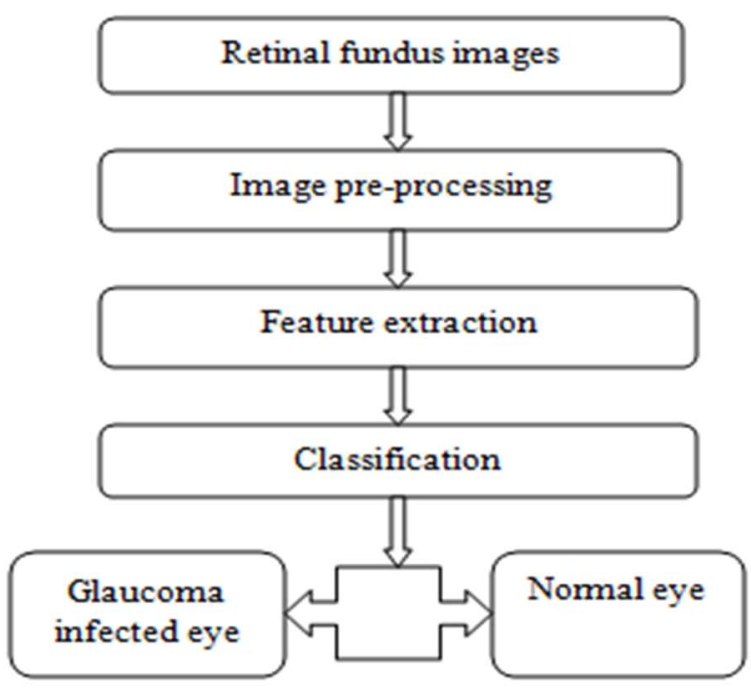

Figure 1: General process for the detection of Glaucoma

Table 1: Summary of different Database used for detection of Glaucoma

\begin{tabular}{|c|c|c|c|}
\hline S.No. & Authors & No. of Images & Database \\
\hline 1) & Agarwal et al [13] & 110 images & $\begin{array}{l}\text { Local database } \\
\text { (Venue Eye Research Centre, New Delhi) }\end{array}$ \\
\hline 2) & Pruthiet al [14] & $\begin{array}{c}\text { 10normal/10 } \\
\text { Glaucoma }\end{array}$ & \\
\hline 3) & Virket al [15] & 50 images & Local Physician \\
\hline 4) & Gopalkrishanet al [16] & 200 images & RIGA \\
\hline 5) & Ayubet al [17] & 100 images & $\begin{array}{l}\text { Local database } \\
\text { (Armed forces institute of ophthalmology) }\end{array}$ \\
\hline 6) & Sakthivelet al [18] & 44 images & $\begin{array}{c}\text { Local database } \\
\text { (Aravind Eye Hospital, Madurai, India.) }\end{array}$ \\
\hline 7) & Kolar etal [19] & 30 images & NA \\
\hline 8) & Acharya et al.[20] & 60 images & $\begin{array}{c}\text { Local database } \\
\text { (Kasturba Medical College, Manipal, India ) }\end{array}$ \\
\hline 9) & Acharyaet al[21] & 510 images & $\begin{array}{c}\text { Local database } \\
\text { (Kasturba Medical College, Manipal, India ) }\end{array}$ \\
\hline 10) & Shishir etal [22] & $\begin{array}{l}505 \text { images (Public } \\
\text { Database) and } 60 \\
\text { images (Private } \\
\text { database) }\end{array}$ & $\begin{array}{c}\text { http://medimrg.webs.ull.es/. (Public Database) } \\
\text { Kasturba Medical College, Manipal, India.(Private } \\
\text { Database) }\end{array}$ \\
\hline 11) & Krishnan et al [23] & 60 images & $\begin{array}{c}\text { Kasturba Medical College, Manipal, India.(Private } \\
\text { Database) }\end{array}$ \\
\hline 12) & Nyul et al [24] & NA & Erlangan Glaucoma Registry \\
\hline
\end{tabular}




\begin{tabular}{|c|c|c|c|}
\hline 13) & Bock et al [25] & NA & NA \\
\hline 14) & Mookiah et al [26] & NA & NA \\
\hline 15) & Dua et al [27] & 60 images & $\begin{array}{c}\text { Kasturba Medical College, Manipal, India.(Private } \\
\text { Database) }\end{array}$ \\
\hline 16) & Beaula et al [28] & NA & NA \\
\hline 17) & Patil et al [29] & NA & Atharva Eye Care Hospital, Pune \\
\hline 18) & Dey et al [30] & NA & NA \\
\hline 19) & Singh et al [31] & 220 images & $\begin{array}{l}\text { http://www.tf.fau.de/ (public database) and } \\
\text { TechnischeFakultat (private database) }\end{array}$ \\
\hline
\end{tabular}

Step 2: Second step for the detection involves the pre-processing of the data i.e. noise removal and balancing other loopholes present in the image. The main motive of pre-processing is an improvement of the image data that suppresses unveiling distortions or enhances some image feature which are important for further processing steps, although geometric transforms of images (example rotation, scaling and translation) are classified among preprocessing methods. Different methods which are commonly used for this purpose are Histogram equalization, extraction of red, blue and green channel from the image, color enhancement, morphological operations, Fractal Analysis and much more. Histogram equalization is defined as a processor which was used for modifying image intensities to improve the contrast. Fractal analysis is a process where important parameter is the color of image. Fractal dimension is spontaneously determined for all levels of chosen channel of color information i.e. Red, Green, Blue, Hue, Saturation etc. Another method for the preprocessing is the extraction of color channels from the images. These channels are termed as Red channel, Blue channel, Green channel and Gray channel which were further used for the extraction of features from the image. Morphological can be explained as the set of image processing methods which characterize images on the basis of shapes [32, 33, 34, 35]. These methods use a structuring element as a mask in the input image which results in the same size output image. Basic morphological operations used are dilation and erosion [36, 37].

Table 2 shows the summary of different pre-processing techniques used for detection of Glaucoma till yet. Out of the different pre processing techniques the best method for preprocessing is extraction of Red, Blue, Green and Gray Channel Extraction. In fundus images, blood vessels in eye appeared like a network structure. So, to achieve success in detecting blood vessels accurately, different channels are extracted. Green channel gives highest accuracy when compared with other channels because it gives the finest results in the contrast for extracting the vessels which appear darker in light background [38].

Table 2: Summary of different pre-processing techniques used for Detection of Glaucoma

\begin{tabular}{ccc} 
S.No. & Authors & Pre-processing techniques \\
\hline 1$)$ & Agarwal et al $[13]$ & $\begin{array}{c}\text { Red , Green and Blue channel } \\
\text { extraction }\end{array}$
\end{tabular}


2) Pruthiet al [14] Anisotropic diffusion filter

\begin{tabular}{|c|c|c|}
\hline 3) & Virket al[15] & NA \\
\hline 4) & Gopalkrishanet al [16] & Localized Gaussian Smoothing \\
\hline 5) & Ayubet al [17] & $\begin{array}{c}\text { Morphological operations, } \\
\text { Equalization, Color } \\
\text { Enhancement }\end{array}$ \\
\hline 6) & Sakthivelet al [18] & Gabor filter \\
\hline 7) & Kolar etal [19] & Fractal Analysis \\
\hline 8) & Acharya et al.[20] & $\begin{array}{c}\text { Radon Transform, Histogram } \\
\text { Equalization }\end{array}$ \\
\hline 9) & Acharyaet al[21] & Histogram Equalization \\
\hline 10) & Shishir etal [22] & $\begin{array}{l}\text { Red ,Green and Blue channel } \\
\text { extraction }\end{array}$ \\
\hline 11) & Krishnan et al [23] & $\begin{array}{c}\text { Histogram equalization, Radon } \\
\text { transformation }\end{array}$ \\
\hline 12) & Nyul et al [24] & $\begin{array}{l}\text { Illumination correction, Vessel } \\
\text { removal, Papilla normalization }\end{array}$ \\
\hline 13) & Bock et al [25] & Normalization \\
\hline 14) & Mookiah et al [26] & NA \\
\hline 15) & Dua et al [27] & Histogram equalization \\
\hline 16) & Beaula et al [28] & $\begin{array}{l}\text { Red ,Green and Blue channel } \\
\text { extraction }\end{array}$ \\
\hline 17) & Patil et al [29] & Histogram equalization \\
\hline 18) & Dey et al [30] & NA \\
\hline 19) & Singh et al [31] & NA \\
\hline
\end{tabular}

Step 3: Third step can be termed as the Feature extraction step which involves different techniques like wavelet methods $[37,38,39,40]$, filters, pixel intensity values and histogram models. Feature extraction is defined as method which is used to convert the visually extractable and non-extractable features into respective mathematical expressions. These expression ns, if based on shape then known as morphological features and if they are based on intensity distribution then termed as texture features. Methods based on the intensity distribution are (i) Statistical methods (ii) Signal Processing based Techniques, (EWT is the best example of this technique) and (iii) Transform based methods. Discrete transform, Fourier transform are some of the common transform based techniques used in the detection process. Different features are extracted like CDR, correntropy features, mean, standard deviation and open-angle parameters. Many proposed method uses change in CDR value as a feature for the detection of Glaucoma at early stage. The best extraction technique is EWT based correntropy features on the accuracy value.EWT, a signal decomposition technique can be defined as the signaldependent method which does not require any predefined basis function like Fourier and Wavelet transform. It acts as a band pass filter. The empirical scaling function $\xi_{\mathrm{m}}(\mathrm{W})$ and the empirical wavelets $\zeta_{\mathrm{m}}(\mathrm{W})$ are predefined. Correntropy are termed as a nonlinear kernelized 
similarity measure. This feature excellently captured the restrained variations in the pixel intensitiesand gives high classification accuracy.

Step 4: Last step or image classification (whether normal or glaucoma) is the analysis done using different features and consolidate the data for the classification. Classification is the techniques of combining the testing samples with similar features into same levels, where these levels are termed as classes. There are two categories of classification viz. supervised classification and unsupervised classification. Supervised classification is one in which training set is predefined else it is termed as unsupervised classification $[38,39,40]$. There are different types of classifications like SVM classifier, Bayes classifier, K-mean clustering classifier and many more depending upon the data used for the analysis. SVM gives the highest classification accuracy when used. Based on all the steps discussed above, CAD system was designed for the detection of Glaucoma. These systems use various techniques for detection process which gives different percentage of accuracy. Table 3 shows the comparison of different techniques used for the Detection of Glaucoma. The different papers were reviewed on the detection of Glaucoma; CDR was termed as important feature for the detection. CDR was calculated using different classifiers like thresholding, SVM, Least square minimization, K-mean clustering which results in lessaccuracy. Later it was seen that when 2D EWT and correntropy method (feature extraction method) with Least-SVM (classifier) was used, gives more accuracy over the other methods.

Table 3:Comparison of different methods used for the Detection of Glaucoma

\begin{tabular}{|c|c|c|c|c|c|c|}
\hline S.No. & Authors & $\begin{array}{c}\text { Methods given by } \\
\text { authors }\end{array}$ & $\begin{array}{l}\text { Images } \\
\text { Number }\end{array}$ & $\begin{array}{l}\text { Features } \\
\text { extracted }\end{array}$ & Classifier & $\begin{array}{c}\text { Accuracy } \\
(\%)\end{array}$ \\
\hline 1. & $\begin{array}{c}\text { Agarwal et al } \\
{[13]}\end{array}$ & $\begin{array}{c}\text { Adaptive } \\
\text { thresholding }\end{array}$ & 110 images & $\begin{array}{l}\text { CDR, mean, } \\
\text { standard } \\
\text { deviation }\end{array}$ & Thresholding & $90 \%$ \\
\hline 2. & Pruthiet al [14] & CDR Calculation & $\begin{array}{c}\text { 10normal/10 } \\
\text { glaucoma }\end{array}$ & $\mathrm{CDR}$ & SVM & $98.12 \%$ \\
\hline 3. & Virket al $[15]$ & CDR Determination & 50 images & CDR & Thresholding & $95 \%$ \\
\hline 4. & $\begin{array}{c}\text { Gopalkrishanet } \\
\text { al [16] }\end{array}$ & $\begin{array}{l}\text { Segment OD } \\
\text { boundary }\end{array}$ & 200 images & CDR & $\begin{array}{l}\text { Least square } \\
\text { minimization }\end{array}$ & $68 \%$ \\
\hline 5. & Ayubet al [17] & $\begin{array}{l}\text { Optic disc and Cup } \\
\text { segmentation using } \\
\text { K-mean clustering }\end{array}$ & 100 images & CDR & $\begin{array}{c}\text { K-mean } \\
\text { Clustering }\end{array}$ & $92 \%$ \\
\hline 6. & $\begin{array}{c}\text { Sakthivelet al } \\
{[18]}\end{array}$ & Histogram & 44 images & $\mathrm{LBF}$ & $\begin{array}{c}\text { Euclidean } \\
\text { Distance }\end{array}$ & $95.45 \%$ \\
\hline 7. & Kolar etal [19] & Fractal Dimensions & 30 images & $\begin{array}{c}\text { Fractal and } \\
\text { power spectral } \\
\text { features }\end{array}$ & SVM & $74 \%$ \\
\hline 8. & $\begin{array}{c}\text { Acharya et } \\
\text { al. }[20]\end{array}$ & $\begin{array}{c}\text { Diagnosis using } \\
\text { texture and HOS } \\
\text { feature }\end{array}$ & 60 images & HOS and texture & $\begin{array}{l}\text { Random- } \\
\text { forest }\end{array}$ & $91 \%$ \\
\hline 9. & $\begin{array}{c}\text { Acharyaet } \\
\text { al }[21]\end{array}$ & $\begin{array}{c}\text { Using Gabor } \\
\text { Transformations }\end{array}$ & 510 images & Gabor features & SVM & $93.1 \%$ \\
\hline 10. & Shishir etal & Using EWT and & 505 images & Correntropy & LS-SVM & $98.33 \%$ \\
\hline
\end{tabular}




\begin{tabular}{|c|c|c|c|c|c|c|}
\hline & {$[22]$} & Correntropy features & $\begin{array}{c}\text { (Public } \\
\text { Database) } \\
\text { and } 60 \\
\text { images } \\
\text { (Private } \\
\text { database) }\end{array}$ & features & & \\
\hline 11. & $\begin{array}{c}\text { Krishnan et al } \\
\text { [23] }\end{array}$ & $\begin{array}{l}\text { Detection using } \\
\text { texture, DWT } \\
\text { energy and HOS } \\
\text { features }\end{array}$ & 60 images & $\begin{array}{l}\text { HOS and energy } \\
\text { features }\end{array}$ & SVM & $91.67 \%$ \\
\hline 12. & Nyul et al [24] & Glaucoma detection & NA & PCA & SVM & $80 \%$ \\
\hline 13. & Bock et al [25] & $\begin{array}{c}\text { Texture analysis for } \\
\text { detection }\end{array}$ & NA & $\begin{array}{c}\text { Pixel intensity } \\
\text { values, FFT } \\
\text { coefficients } \\
\end{array}$ & SVM & $86 \%$ \\
\hline 14. & $\begin{array}{c}\text { Mookiah et al } \\
{[26]}\end{array}$ & NA & NA & $\begin{array}{c}\text { HOS and } \\
\text { wavelet }\end{array}$ & SVM & $95 \%$ \\
\hline 15. & Dua et al [27] & $\begin{array}{l}\text { Detection using } \\
\text { texture features }\end{array}$ & 60 images & $\begin{array}{c}\text { Energy } \\
\text { signatures }\end{array}$ & SVM & $93.33 \%$ \\
\hline 16. & $\begin{array}{c}\text { Beaula et al } \\
\text { [28] }\end{array}$ & $\begin{array}{l}\text { Detection using } \\
\text { texture features }\end{array}$ & NA & Correntropy & SVM & $74 \%$ \\
\hline 17. & Patil et al [29] & Using CDR & NA & CDR & SVM & NA \\
\hline 18. & Dey et al [30] & NA & NA & NA & SVM & $96 \%$ \\
\hline 19. & $\begin{array}{c}\text { Singh et al } \\
\text { [31] }\end{array}$ & $\begin{array}{l}\text { Detection of } \\
\text { glaucoma }\end{array}$ & 220 images & $\begin{array}{l}\text { Red, Green and } \\
\text { Blue values }\end{array}$ & SVM & $97 \%$ \\
\hline
\end{tabular}

\section{CONCLUSION AND FUTURE WORK}

Glaucoma detection techniques have been studies thoroughly and it has been concluded that the accuracy of EWT with Correntropy features based method and CDR with SVM is better than other reported methods. In future, the performance of these methods can be tested on the same data set using same classifiers.

\section{REFERENCES.}

[1] https://www.emedicinehealth.com/normal-tension glaucoma/article em.htm

[2] https://www.glaucoma.org/glaucoma/types-of-glaucoma.php

[3] GBD 2015 Disease and Injury Incidence and Prevalence, Collaborators. (8 October 2016). "Global, regional, and national incidence, prevalence, and years lived with disability for 310 diseases and injuries, 1990-2015: a systematic analysis for the Global Burden of Disease Study 2015". Lancet. 388 (10053): 1545-1602

[4] Resnikoff S, Pascolini D, Etya'ale D et al. (2004) Global data on visual impairment in the year 2002. Bull World Health Organ 82:844-851.

[5] Quigley HA, Broman AT. The number of people with glaucoma worldwide in 2010 and 2020. Br J Ophthalmol. $2006 ; 90(3): 262-267$.

[6] Mantravadi, AV; Vadhar, N (September 2015). "Glaucoma". Primary Care. Saunders (Elsevier). 42 (3): $437-49$.

[7] https://www.glaucoma.org/glaucoma/types-of-glaucoma.php

[8] https://www.webmd.com/eye-health/glaucoma-eyes

[9] https://www.glaucoma.org/glaucoma/normal-tension-glaucoma.php

[10] https://www.aao.org/eyenet/article/diagnosis-treatment-ofnormaltension-glaucoma

[11] https://www.emedicinehealth.com/normaltension_glaucoma/articem.htm

[12] Tehmina Khalil, Samina Khalid and AdeelM.Syed "Review of Machine Learning Techniques for Glaucoma Detection and Prediction” Science and Information Conference 2014 August 27-29, 2014 | London, UK.8 
[13] A.Agarwal, S.Gulia, S.Choudhary, M.K.Dutta, R.Burget, "Automatic Glaucoma Detection using Adaptive Threshold based Technique in Fundus Image",38th International Conference on Telecommunications and Signal Processing (TSP), 2015

[14] J.Pruthi, Dr.S.Mukherjee , "Computer Based Early Diagnosis of Glaucoma inBiomedical Data Using Image Processing and Automated Early Nerve Fiber Layer Defects Detection using Feature Extraction in Retinal Colored Stereo Fundus Images" , International Journal of Scientific \& Engineering Research, Volume 4, Issue 4, April-2013

[15] J.K.Virk, M.Singh and M.singh,"Cup-to-Disk Ratio (CDR) Determination for Glaucoma Screening”, 1st International Conference on Next Generation Computing Technology, 2015

[16] A. Gopalakrishnan, A .Almazroa ,K. Raahemifar, V.Lakshminarayanan , "Optic Disc Segmentation using Circular Hough Transform and Curve Fitting ", 2nd International Conference on Opto-Electronics and Applied Optics (IEM OPTRONIX), 2015

[17] J.Ayub, J.Ahmad, J.Muhammad , "Glaucoma Detection through Optic Disc and Cup Segmentation using Kmean Clustering" 2016 International Conference on Computing, Electronic and Electrical Engineering (ICE Cube)

[18] Sakthivel, Karthikeyan, and Rengarajan Narayanan. "An Automated Detection of Glaucoma Using Histogram Features.” International Journal of Ophthalmology 8.1 (2015): 194-200. PMC. Web. 13 Nov. 2017.

[19] R. Kolar, J. Jan, Detection of glaucomatous eye via color fundus images using fractal dimensions, Radio Eng. 17 (3) (2008) 109-114.

[20] U.R. Acharya, S. Dua, X. Du, S.V. Sree, C.K. Chua, Automated diagnosis of glaucoma using texture and higher order spectra features, IEEE Trans. Inf. Technology. Biomedical 15 (3) (2011) 449-455.

[21] Acharya, U. R., Ng, E. Y. K., Eugene, L. W. J., Noronha, K. P., Min, L. C., Nayak, K. P., \&Bhandary, S. V. (2015). Decision support system for the glaucoma using Gabor transformation. Biomedical Signal Processing and Control, 15, 18-26.

[22] M.Shishir , P. Ram Bilas , U. Rajendra Acharya , "Automated Diagnosis of Glaucoma Using Empirical Wavelet Transform and Correntropy Features Extracted From Fundus Images" , IEEE Journal Of Biomedical And Health Informatics, Vol. 21, No. 3, P.P. 803-813 , May 2017

[23] M. Krishnan,. M. R., \& Faust, O. (2013). Automated glaucoma detection using hybrid feature extraction in retinal fundus images. Journal of Mechanics in Medicine and Biology, 13(01), 1350011.

[24] L. G. Nyúl, (2009, October). Retinal image analysis for automated glaucoma risk evaluation. In Proc. of SPIE Vol (Vol. 7497, pp. 74971C-1).

[25] R. Bock, J. Meier, L. G. Nyl, and G. Michelson, "Glaucoma risk index: Automated glaucoma detection from color fundus images,” Med. Image Anal., vol. 14, pp. 471-481, 2010

[26] M. R. K. Mookiah, U. R. Acharya, C. M. Lim, A. Petznick, and J. S. Suri, "Data mining technique for automated diagnosis of glaucomausing higher order spectra and wavelet energy features," Knowl.-Based Syst., vol. 33, pp. 73-82, 2012.

[27] S Dua,., U. R Acharya,., P., Chowriappa, \& Sree, S. V. (2012). Wavelet-based energy features for glaucomatous image classification. Ieee transactions on information technology in biomedicine, 16(1), 8087.

[28] L Beaula., M Asirvatham., T Kalimuthu. , "Earlier Detection of Glaucoma using Empirical Wavelet Transform”, International Journal for Research in Applied Science \& EngineeringTechnology (IJRASET), vol 5 , pp 1311-1316, Apr 2017.

[29] H.P. Patil, V.S Kamkhedhar. , "Analysis of Human Retinal Images for Automated Glaucoma Screening" , International Journal for Research in Applied Science \& EngineeringTechnology (IJRASET), vol 2 , pp 371-377, Dec 2014.

[30] A Dey and S K. Bandyopadhyay, "Automated Glaucoma Detection Using Support Vector Machine Classification Method," 2016, British Journal of Medicine \& Medical Research (BJMMR), Kolkata

[31] P Singh and B. Marakarkandy, (2017). Comparitive Study of Glucoma Detection using Different Classifiers.

[32] S Jain, "Classification of EGF and Insulin Receptors using Gabor Wavelet Transform", International Journal of Advanced Research Trends in Engineering and Technology (IJARTET), 4(11), 21-25, 2017.

[33] S.Sharma, S Jain, S.Bhusri, "Two Class Classification of Breast Lesions using Statistical and Transform Domain features", Journal of Global Pharma Technology (JGPT), 9(7), pp. 18-24, 2017.

[34] S.Bhusri, S Jain, “Analysis of Breast Lesions Using Laws' Mask Texture Features ”, December $22^{\text {nd }}-24^{\text {th }}$, 2016,pp. 56- 60, 2016 Fourth International Conference on Parallel, Distributed and Grid Computing (PDGC), Jaypee University of Information technology, Waknaghat, Solan, H.P, India 
[35] S Rana, S Jain, J Virmani "Classification of Focal Kidney lesions using Wavelet-Based Texture Descriptors", International Journal of Pharma and Bio Sciences, 7(3) B, 646-652, July-Sep 2016.

[36] A Dhiman, A Singh, S Dubey, SJain, "Design of Lead II ECG Waveform and Classification Performance for Morphological features using Different Classifiers on Lead II ", Research Journal of Pharmaceutical, Biological and Chemical Sciences (RJPBCS),7(4), 1226- 1231: July-Aug 2016

[37] S Bhusri , S Jain, J Virmani , "Classification of breast lesions using the difference of statistical features" Research Journal of Pharmaceutical , Biological and Chemical Sciences (RJPBCS) ,7 (4), 1365-1372: JulyAug 2016

[38] Amandeep, Shruti Jain, SahilBhusri, "CAD for Two Class Classification of Lung Cancer using Statistical Features", International Journal of Pharmaceutical Sciences Review and Research (IJPSRR), 45(2), pp 5560, 2017 (August).

[39] S Rana, S Jain, J Virmani, "SVM-Based Characterization of Focal Kidney Lesions from B-Mode Ultrasound Images", Research Journal of Pharmaceutical, Biological and Chemical Sciences (RJPBCS), 7(4), 837- 846: July- Aug, 2016.

[40] S Bhusri , S Jain, J Virmani,"Breast Lesions Classification using the Amalagation of morphological and texture features "International Journal of Pharma and BioSciences (IJPBS), 7(2) B , 617-624, Apr-Jun 2016. 